\title{
Design and applications of a home-built in situ FT-Raman spectroscopic cell
}

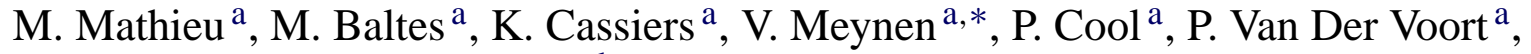 \\ B.M. Weckhuysen ${ }^{b}$, R.A. Schoonheydt ${ }^{\text {c }}$, E.F. Vansant ${ }^{\mathrm{a}}$ \\ a Laboratory of Adsorption and Catalysis, Department of Chemistry, University of Antwerpen (U.A.), Universiteitsplein 1, 2610 Wilrijk, Belgium \\ ${ }^{\mathrm{b}}$ Department of Inorganic Chemistry and Catalysis, Debye Institute, University of Utrecht, Sorbonnelaan 16, \\ PO Box 80083, 2508 TB Utrecht, The Netherlands \\ ${ }^{c}$ Departement Interfasechemie, Centrum voor Oppervlaktechemie en Katalyse, K.U.Leuven, Kardinaal Mercierlaan 92, 3001 Heverlee, Belgium
}

Received 9 January 2004; accepted 19 February 2004

\begin{abstract}
In the field of heterogeneous catalysis, in situ spectroscopy is one of the topics with growing interest. The characterization of a catalyst under working conditions is essential to identify the catalytic active site and to study the relation between the surface structure of a catalyst and its catalytic performance. For the first time, the design of an in situ spectroscopic cell for FT-Raman is presented and its performance is demonstrated by monitoring the thermal conversion of as synthesized mesoporous titanium and by characterizing the molecular surface structure of the vanadium oxides grafted on MCM-48 after exposure to a probe molecule. The results in both cases indicate that the in situ FT-Raman cell is a promising technique for characterizing the molecular surface structure of catalyst materials.
\end{abstract}

(C) 2004 Elsevier B.V. All rights reserved.

Keywords: FT-Raman; In situ spectroscopy; Heterogeneous catalysis; Mesoporous titanium; Vanadia-MCM-48

\section{Introduction}

Raman spectroscopy is a universal analytical technique for the identification and structural characterization of molecular species in gases, liquids and solids, based on the inelastic scattering of monochromatic laser radiation. It is a particularly powerful tool in the field of heterogeneous catalysis. Heterogeneous catalysts play a crucial role in industrial and environmental chemistry. Many processes rely on the use of catalysts in one or several reaction steps. Most heterogeneous catalysts are supported transition metal oxides, which consist of a two-dimensional overlayer of the active transition metal oxide, supported on the surface of another oxide (which is usually referred to as carrier or support, e.g. silica, alumina, titania). In the last decades, various spectroscopic techniques have been developed in order to characterize the nature of a catalyst system in detail. Raman has been used successfully in the characterization of various supported transition metal oxide catalyst systems (e.g. vana-

\footnotetext{
* Corresponding author. Tel.: +32-3820-2380; fax: +32-3820-2374.

E-mail address: vera.meynen@ua.ac.be (V. Meynen).
}

dium [1-3], molybdenum [4], chromium [5], tungsten, etc). It is an excellent technique for the (in situ) characterization of catalysts, as it provides several advantages:

1. It is non-destructive, it does not require any special sample preparation and samples of any size and shape can be examined.

2. Raman band positions yield direct information on metal-oxygen bond distances and the coordination of the central metal ion (in comparison with metal oxide reference compounds).

3. The materials that act as support for the active transition metal oxide are generally poor raman scatterers, which is an important advantage in the characterization of the supported oxide phase.

In recent years, research in the field of heterogeneous catalysis is oriented towards in situ spectroscopic investigations, i.e. the characterization of a catalyst under working conditions (generally in a stream of reactants at high temperatures). Studying changes in the molecular structure, coordination geometry and/or oxidation state of a catalyst during the catalytic reaction is of significant importance 
for the identification of the active components on the catalyst's surface and for a fundamental understanding of structure-activity/selectivity relationships. Therefore, researchers are currently working on spectroscopic cells that are suited to characterize a catalyst under process conditions.

In general, the optical set-up of a Raman instrument is either designed for dispersive or Fourier transform means [6]. In the literature, in situ Raman cell designs have only been described for dispersive devices [7-11], in contrast to Fourier transform. However, FT-Raman spectroscopy has two main advantages over conventional Raman spectroscopy: it is normally much faster and sample fluorescence is very rare at the $1064 \mathrm{~nm}$ excitation frequency. Therefore, it offers the ability to quickly analyse a very wide variety of sample types and to collect a full high resolution spectral range in a single measurement.

In this paper in situ Raman cell designs are reviewed and for the first time the development of an in situ spectroscopic cell for Fourier transform Raman is discussed. Furthermore, the novel spectroscopic cell is used in two case studies: the thermal conversion of mesoporous titania and the interaction between probe molecules with catalytically active vanadium oxides on the surface of MCM-48 at elevated temperatures.

\section{Design of an in situ Raman cell}

The in situ characterization of a working catalyst requires a well-designed spectroscopic cell. In order to obtain relevant catalytic conditions, the cell design should make it possible to treat the catalyst at the desired reaction temperature and pressure, to bring the catalyst in contact with the reactant and to focus the raman laser on the sample and collect the scattered raman radiation.

A literature overview of different cell designs and studied catalytic reactions is presented in Table 1. Basically, in situ Raman cells consist of a sample holder in which the catalyst is held, a gas inlet and outlet system containing the reactant (usually the reactant is introduced in an inert gas flow, like
$\mathrm{He}$ or $\mathrm{N}_{2}$ ), a furnace that surrounds the sample holder and an optical window for the Raman measurement. In fact, the main difference between the various cell systems is the nature of the catalyst sample during the measurement. On the one hand, the catalyst can be placed as a pellet or powder on top of a ceramic shaft [7,12-16] or a ceramic cup [17] (surrounded by a quartz cell). An advantage of using pressed wafers placed on a ceramic shaft, is that the sample pellet is rotated during the measurement, which avoids excessive heating of the sample by the Raman laser. A disadvantage is however that in these kinds of systems the reactant gas stream is not flowing through the catalyst bed or pellet. As a result, irreproducible flow patterns of reactants and reaction products can occur inside the cell, therefore disturbing the equilibrium situation. Hence, the Raman spectrum of the studied catalyst will depend on the position at which the raman laser is focused.

A second type of in situ Raman system uses a granulated catalyst placed in a fixed bed quartz reactor $[8,11,18,19]$. The reactant stream is flowing through the catalyst bed and the laser beam is focused on the catalyst by means of an optical window. Obviously, the conditions obtained in this fixed bed system are much more comparable with the conditions obtained in real catalytic processes.

As inferred from Table 1, up to now only dispersive Raman instruments are used for in situ characterization of catalysts. Because of the frequency dependence (Raman intensity: $\sim v^{4}$ ), shorter laser wavelengths are preferred because these raman instruments have the highest intrinsic sensitivity. Still, the problems arising from sample fluorescence, photodecomposition of reaction products or intermediates, and the lowering of signal intensities due to a strong absorption of the catalyst supports, show that near-IR FT-Raman is a valuable and complementary technique for in situ characterization. Therefore, an in situ cell has been constructed for use in FT-Raman.

Bearing in mind the advantages and disadvantages of the different cell designs on the one hand and the dimensions of the FT-Raman instrument on the other hand, a fixed bed

Table 1

Literature overview of different cell designs and studied catalytic reactions

\begin{tabular}{|c|c|c|c|}
\hline Reference (alphabetical order) & Laser source & Reaction under study & Catalyst bed \\
\hline Boulova [17] & $514.5 \mathrm{~nm} \mathrm{Ar}$ ion laser & $\mathrm{CH}_{4}, \mathrm{CO}$ and $\mathrm{NO}_{2}$ adsorption on $\mathrm{WO}_{3}$ & $\begin{array}{l}\text { Sample pellet } 6 \mathrm{~mm} \\
\text { diameter, } 1.5 \mathrm{~mm} \text { thickness }\end{array}$ \\
\hline Chua [19] & $\begin{array}{l}244 \mathrm{~nm} \text { second harmonic } \\
\text { generation }(\mathrm{SGH}) \text { laser with } \\
\text { a intracavity nonlinear crystal } \\
\text { (BBO, } \beta \text {-barium borate) }\end{array}$ & $n$-Heptane adsorption & Powder sample in fluidized bed \\
\hline Koyano [8] & $514.5 \mathrm{~nm} \mathrm{Ar}$ ion laser & $n$-Butane oxidation & Powder sample in fixed bed \\
\hline Mestl [11] & $\begin{array}{l}532.0 \mathrm{~nm} \text { Nd-YAG laser, } \\
\text { frequency doubled }\end{array}$ & NO decomposition & Powder sample in fixed bed \\
\hline Wachs [15] & $514.5 \mathrm{~nm} \mathrm{Ar}$ ion laser & Methane and methanol oxidation & $\begin{array}{l}\text { Rotating sample disc, } \\
\text { mounted on ceramic shaft } \\
(1000-2000 \mathrm{rpm})\end{array}$ \\
\hline Wang [18] & $514.5 \mathrm{~nm} \mathrm{Ar}$ ion laser & Methanol oxidation over $\mathrm{Ag}$ & Powder sample in fixed bed \\
\hline Went [9] & $488.0 \mathrm{~nm}$ Ar ion laser & Selective catalytic reduction of nitric oxides & Powder sample in fixed bed \\
\hline
\end{tabular}




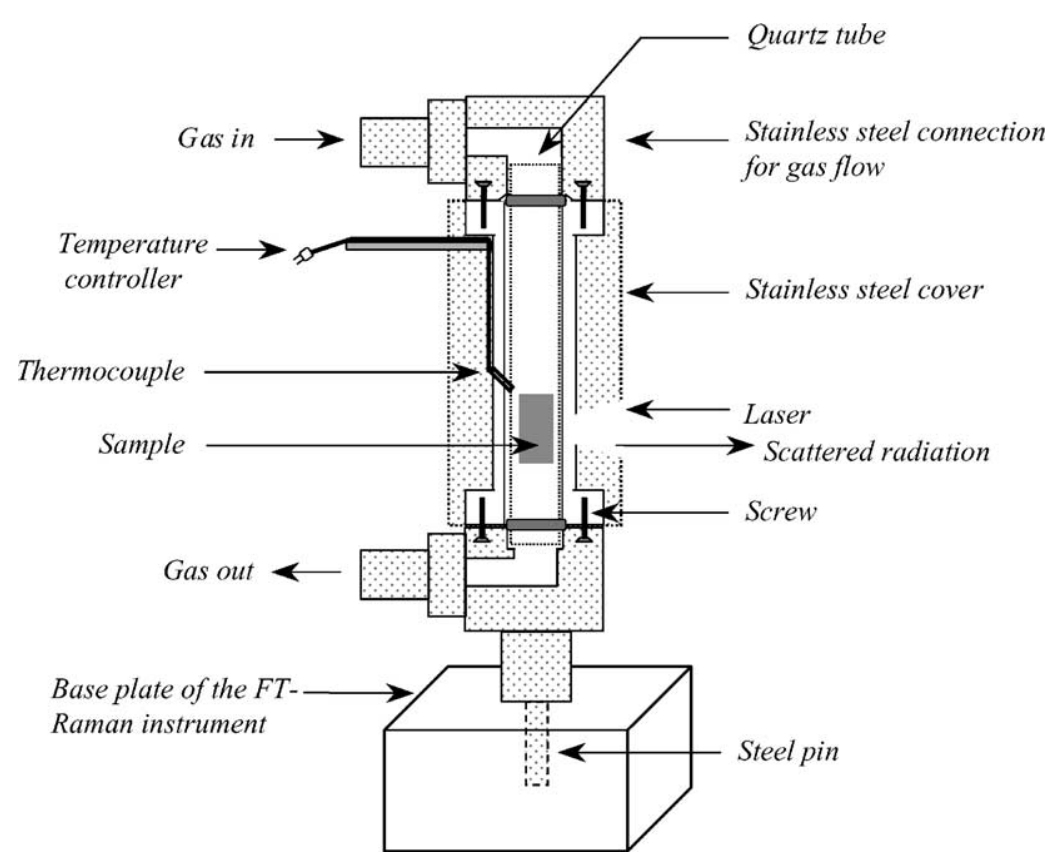

Fig. 1. Schematic representation of the home-built FT-Raman in situ cell.

approach is chosen for the design of the novel in situ cell. A schematic diagram of the in situ spectroscopic cell for application in FT-Raman is represented in Fig. 1. The catalyst sample (powder) is held between two glass wool plugs in a quartz tube, which is surrounded by a cylindrical furnace that is controlled by a temperature controller (Eurotherm). The furnace is isolated by glass wool and a stainless steel cover. The top and bottom of the quartz reactor tube are connected to the inlet and outlet of a gas flow setup. The reactor is attached vertically to the baseplate of the Nicolet Nexus FT-Raman instrument. The laser beam is focused onto the catalyst through a window in the stainless steel cover and the cylindrical furnace. The cell allows to perform Raman spectroscopy on samples, which can be heated up to $400{ }^{\circ} \mathrm{C}$ under a controlled atmosphere. The Spectra are recorded on a Nicolet Nexus 670 bench equipped with a Raman module, a $1064 \mathrm{~nm}$ Nd-YAG excitation laser and a Ge detector. Measurements are performed in a 180 degree reflective sampling configuration. An ellipsoidal mirror collects and reflects the scattered photons into a filter stage and mirror system. The elastically scattered component is rejected, and the Raman component is directed by the mirror system towards the interferometer (equipped with $\mathrm{a} \mathrm{CaF}_{2}$ beamsplitter) and finally to the Ge detector.

\section{Results and discussion}

The performance of the in situ FT-Raman cell is tested in two series of experiments. The first application deals with the thermal conversion of an as-synthesized material into the final catalyst. Besides a new route to synthesize mesoporous titania, the entire calcination process, going from room tem- perature till $400^{\circ} \mathrm{C}$, is followed in the in situ FT-Raman cell. The characterization of the molecular surface structure of a catalyst in contact with a probe molecule at elevated temperatures is the second application. Hereby MCM-48 grafted with vanadium oxides is used as the catalyst while ethanol is used as the probe molecule.

\subsection{Thermal conversion of as synthesized amorphous titania into ultra stable mesoporous titania with nanosized anatase walls}

Since the first successful combination of sol-gel chemistry and self-assembly in the synthesis of ordered mesoporous silica [20], a variety of different framework compositions have been synthesized [21-24], such as vanadia, titania, zirconia,.... However, framework compositions other than silica are often more susceptible to hydrolysis, redox reactions, or phase transitions accompanied by thermal breakdown of the structural integrity, which makes it much more difficult to remove the templates and create porous materials. Titanium oxide is one of the most attractive targets for mesostructuring because it is used as a catalyst in organic reactions, such as selective oxidations and photocatalytic reactions, in electrochemistry and electro-optics.

A new route to synthesize mesoporous titania, with extremely high thermal stability compared to earlier synthesis methods, has been developed. The mesoporous titania was prepared by using the hexadecyl amine (HA) as the template. The final material was calcined at $400{ }^{\circ} \mathrm{C}$ for $4 \mathrm{~h}$ and exhibited a surface area of $393 \mathrm{~m}^{2} \mathrm{~g}^{-1}$, a pore volume of $0.16 \mathrm{ml} \mathrm{g}^{-1}$ and is denoted as the non-treated sample. Part of this sample was post treated with $\mathrm{NH}_{3}$ before it was calcined. This new post-synthesis step was developed in order 


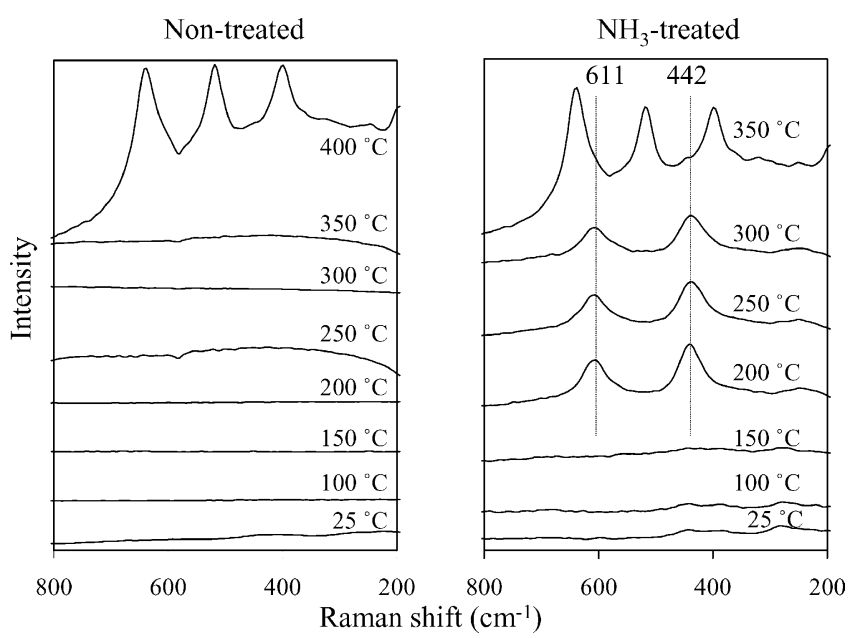

Fig. 2. In situ Raman spectra of non- and $\mathrm{NH}_{3}$-treated titania as a function of the calcination temperature.

to govern stability to the process during calcination. After calcinations at $400{ }^{\circ} \mathrm{C}$, the post-treated sample had a surface area of $435 \mathrm{~m}^{2} \mathrm{~g}^{-1}$, a pore volume of $0.19 \mathrm{ml} \mathrm{g}^{-1}$ and is designated as the $\mathrm{NH}_{3}$-treated sample. More details of the sample synthesis, post synthesis and properties are reported elsewhere [25].

The granulated uncalcined samples $(250-500 \mu \mathrm{m})$ were placed into the cell and were heated with a rate of $5^{\circ} \mathrm{C} \mathrm{min}-1$ from room temperature till $400^{\circ} \mathrm{C}$ in a flow of dry air $\left(50 \mathrm{~cm}^{3} \mathrm{~min}^{-1}\right)$. In situ Raman spectra of these samples were recorded after the samples were kept at a fixed temperature for $1 \mathrm{~h}$ with temperature intervals of $50^{\circ} \mathrm{C}$.

The in situ Raman spectra of the different calcination steps of non-treated and $\mathrm{NH}_{3}$-treated titania are shown in Fig. 2.
The spectra of the non-treated titania do not display any peaks up to $350{ }^{\circ} \mathrm{C}$. At $400{ }^{\circ} \mathrm{C}$ three clear bands at 399,519 and $638 \mathrm{~cm}^{-1}$, characteristic for anatase [26], appear. For the sample treated with $\mathrm{NH}_{3}$, two lines at 442 and $611 \mathrm{~cm}^{-1}$, ascribed to the rutile crystal phase [26], can be observed between 200 and $300^{\circ} \mathrm{C}$. However, upon further increase to $350^{\circ} \mathrm{C}$, the Raman lines related to the rutile phase disappear and the three characteristic anatase bands at 399, 519 and $638 \mathrm{~cm}^{-1}$, can be identified. Due to the intermediate formation of nanosized crystalline domains in the walls before the template is thermally removed, as revealed by in situ Raman spectroscopy, this post-treated titania hybrid shows a unique outstanding thermal stability [25], which is not seen for the non-treated sample.

The temperature increase from room temperature to $400{ }^{\circ} \mathrm{C}$ was also monitored with $\mathrm{XRD}$ and is given in Fig. 3. By a temperature increase from 300 to $400^{\circ} \mathrm{C}$, the disappearance of the $d_{100}$ diffraction line of the non-treated sample is accompanied by the appearance of a single peak at $2 \theta=25.5^{\circ}$, assigned to the massive formation of crystalline anatase. Based on XRD, anatase or any other crystal phase could not be observed for the $\mathrm{NH}_{3}$-treated sample calcined at $400{ }^{\circ} \mathrm{C}$.

Thus, XRD spectra of the $\mathrm{NH}_{3}$-treated sample, measured during the entire calcination process, appeared inadequate to observe any forms of crystalline phases. However, due to higher sensitivity of detection, the collected in situ Raman spectra reveal different forms of nano-crystalline titania before conversion to the final thermally stable mesoporous structure. Based on this in situ technique, the differences in the mechanism of formation during the calcination process of both syntheses could be revealed.

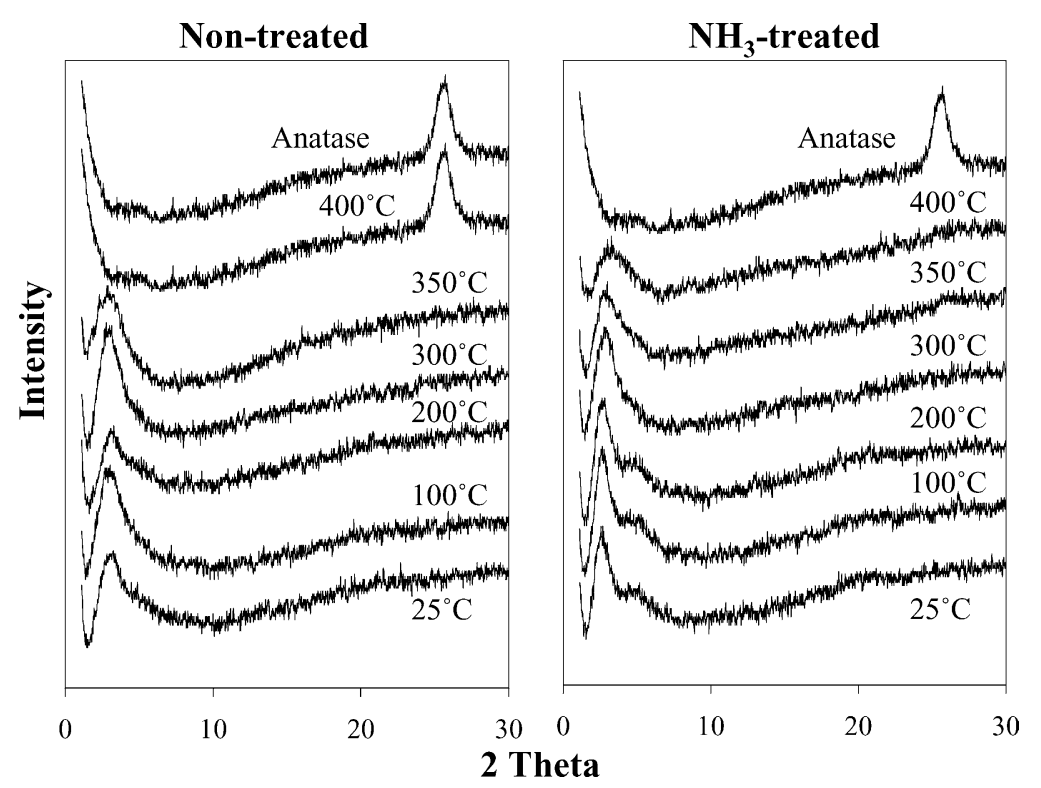

Fig. 3. X-ray diffractograms of different calcination steps of non-and $\mathrm{NH}_{3}$-treated titania and a comparison with the XRD of pure anatase. 


\subsection{Selective ethanol oxidation of vanadium oxides grafted on MCM-48}

In various catalytic processes, not only the surface structure of the catalyst is crucial, but also the nature of the bulk phase. Many micro- and mesoporous inorganic solids (e.g. zeolites, silicas, aluminas) have interesting properties as catalyst supports or adsorbents because of their large internal surface area and pore volume. However, in several industries there is a growing need for materials that can efficiently process large sized molecules, like biochemical macromolecules or heavy crude oils. Through the years, considerable synthetic effort has been devoted to the development of frameworks with large pore diameters and well-ordered pore channels. One of these new materials, which shows unique structural properties is MCM-48 [20]. However, little is known on the surface properties and surface modification of this material.

An important step in the activation of MCM-48 substrates for use in catalytic applications, is the modification with catalytically active transition metals or transition metal oxides. Supported vanadium oxides possess unique properties in several heterogeneous catalytic processes, e.g. the oxidation of sulphur dioxide [27] and the selective catalytic reduction of $\mathrm{NO}_{\mathrm{x}}$ [28]. The MCM-48 supported vanadium oxide catalyst was prepared by using the liquid phase molecular designed dispersion (MDD) of $\mathrm{VO}(\mathrm{acac})_{2}$. The synthesis of MCM-48 [29] and the grafting of metal oxides on a catalytic support by means of the MDD method have been described in detail in previous publications [30-33]. In principle, the complex is anchored to the hydroxyl groups of the support by either hydrogen bonding or by a ligand-exchange mechanism. Treatment in air at elevated temperatures converts the adsorbed acetylacetonate complex into metal oxide species that are chemically bonded on the surface. The process and the reagent are visualized in Fig. 4. Based on the knowledge of the molecular designed dispersion of $\mathrm{VO}(\mathrm{acac})_{2}$ on common oxide supports, new insights on the nature of the

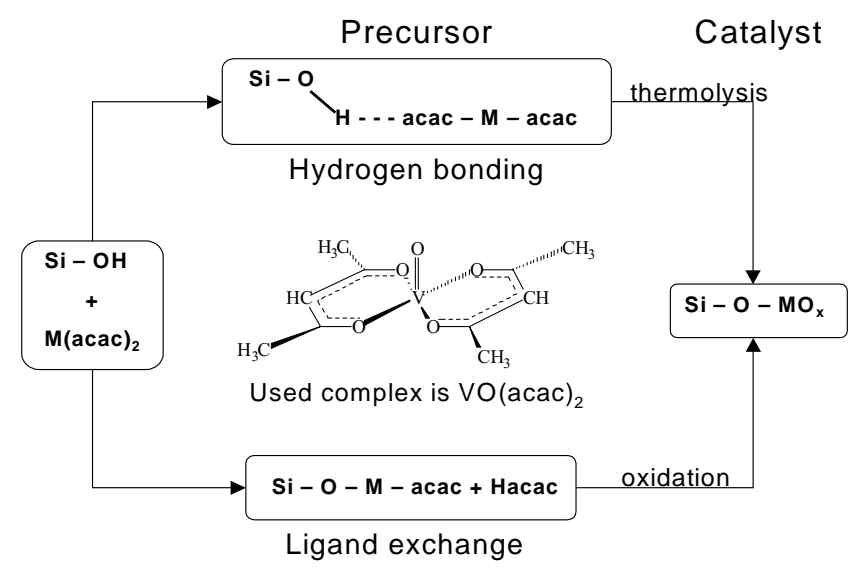

Fig. 4. General overview of the molecular designed dispersion process and the reagent vanadyl acetylacetonate.
MCM-48 surface and the structure of MCM-48 supported vanadium oxide are obtained. Hereby, Raman was applied to monitor the changes of the catalytically active vanadium oxides on a highly porous support, MCM-48, during exposure to probe molecules (ethanol) and thermal treatments.

After calcination at $550{ }^{\circ} \mathrm{C}$ overnight the final catalyst used in this study contains $3.5 \mathrm{wt} \% \mathrm{~V}$ on the surface. The sample exhibits a surface area of $783 \mathrm{~m}^{3} \mathrm{~g}^{-1}$, determined by BET measurements, a pore volume of $0.88 \mathrm{ml} \mathrm{g}^{-1}$ and a pore diameter of $4.5 \mathrm{~nm}$. The in situ Raman spectra under different reaction conditions were obtained by the following procedure. The powdered MCM-48 grafted with vanadium oxides was granulated (particle size: $250-500 \mu \mathrm{m}$ ) and was packed inside the glass reactor tube. Prior to the reaction with ethanol, the spectra of the dehydrated sample were collected after heating the sample to $400{ }^{\circ} \mathrm{C}$ with a rate of $5^{\circ} \mathrm{C} \min ^{-1}$ in a flow of dry air, followed by a cooling period till almost room temperature. After the above treatment, a gaseous stream of $\mathrm{CH}_{3} \mathrm{CH}_{2} \mathrm{OH} / \mathrm{O}_{2} / \mathrm{He}=4 / 8 / 88$ with a flow rate of $100 \mathrm{ml} \mathrm{min}^{-1}$ was introduced into the cell and the Raman spectra under reaction conditions were collected after reaching steady state $\left(\sim 60 \mathrm{~min}\right.$. at $250{ }^{\circ} \mathrm{C}$, which is the reaction temperature). At the end of the ethanol oxidation reaction, Raman spectra were recorded after the ethanol was removed from the feed stream and the used catalyst was reoxidized by flowing dry air at $400^{\circ} \mathrm{C}$ for $1 \mathrm{~h}$. Raman features of the surface metal oxide species appear in the $800-1200 \mathrm{~cm}^{-1}$ region and the surface ethoxy species appear in the $2800-3100 \mathrm{~cm}^{-1}$ region.

The in situ Raman spectra of the $3.5 \mathrm{wt}$ \% vanadium oxide grafted MCM-48 catalyst at various stages of the reaction are shown in Fig. 5. During ethanol oxidation bands at $\sim 2979, \sim 2937$ and $\sim 2890 \mathrm{~cm}^{-1}$ appear. The Raman band at $2979 \mathrm{~cm}^{-1}$ is characteristic for the $\mathrm{C}-\mathrm{H}$ asymmetric stretch of the $\mathrm{CH}_{3}$ units in these ethoxylated surface species. The band at $2937 \mathrm{~cm}^{-1}$ arises from symmetric stretching vibrations of $\mathrm{CH}_{3}$ units in the adsorbed $-\mathrm{OCH}_{2} \mathrm{CH}_{3}$ species. The weak band at $2890 \mathrm{~cm}^{-1}$ is a combination band of $-\mathrm{OCH}_{2} \mathrm{CH}_{3}$ species. Thus, these bands indicate that ethanol is adsorbed as a dissociated surface ethoxy species. Upon removal of the ethanol from the feed stream at $250{ }^{\circ} \mathrm{C}$, the surface ethoxy groups are still present at the surface (not shown). Prior to reaction with ethanol the vanadium oxide grafted MCM-48 exhibits a strong band at $1039 \mathrm{~cm}^{-1}$, which is attributed to the stretching mode of $\mathrm{V}=\mathrm{O}$ in a tetrahedral configuration with three $\mathrm{V}-\mathrm{O}-\mathrm{Si}$ bonds to the MCM-48 surface $[34,35]$ or that the vanadium oxides are in a predominantly isolated $\mathrm{VO}_{4}$ configuration. The Raman features of the surface vanadium oxide species are altered in the presence of adsorbed ethanol molecules. The ethanol flow caused the Raman band of the dehydrated surface vanadium oxide species at $1039 \mathrm{~cm}^{-1}$ to shift towards 1023 , which indicates interaction with the probe molecule, ethanol, while additional bands appear at 1070 and $920 \mathrm{~cm}^{-1}$. These bands are due to the presence of bridging $\mathrm{V}-\mathrm{O}-\mathrm{V}$ bonds. Thus, due to the ethanol oxidation, the polymeric bridging $\mathrm{V}-\mathrm{O}-\mathrm{V}$ func- 


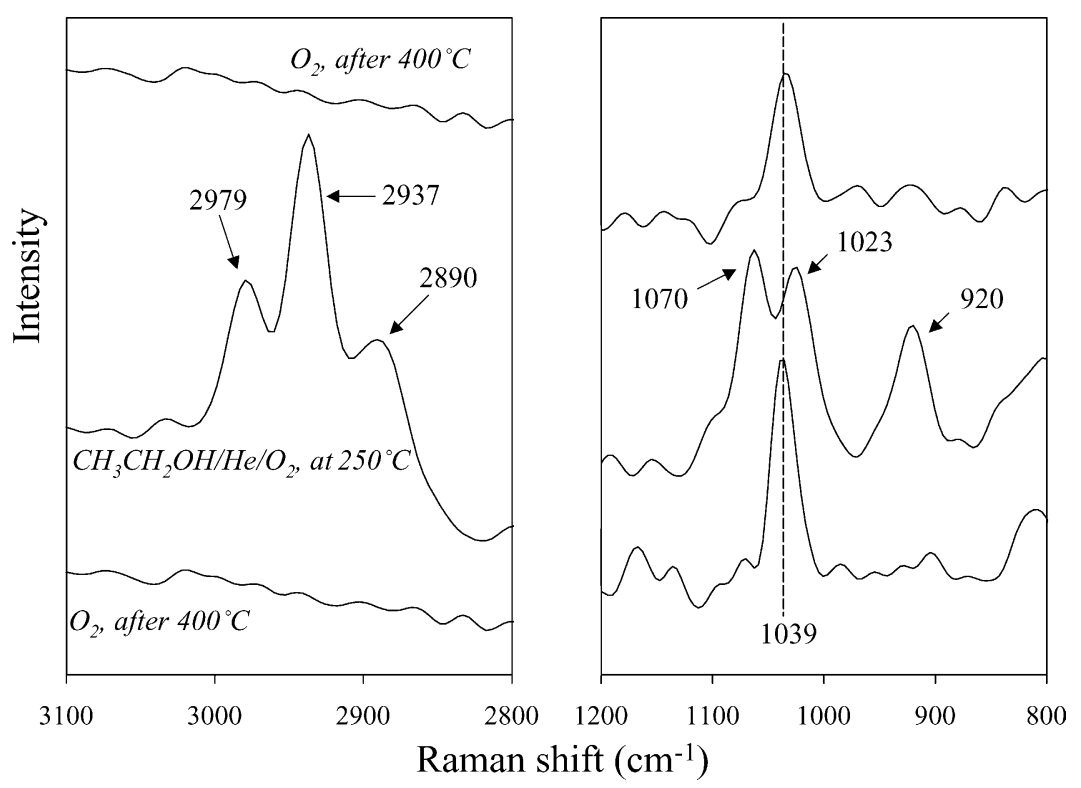

Fig. 5. In situ Raman spectra of a $3.5 \mathrm{wt} . \% \mathrm{VO}_{x}-\mathrm{MCM}-48$ catalyst after thermal treatment at the following conditions: $400^{\circ} \mathrm{C}$ and dry air (bottom), $250{ }^{\circ} \mathrm{C}$ and a stream of $\mathrm{CH}_{3} \mathrm{CH}_{2} \mathrm{OH} / \mathrm{O}_{2} / \mathrm{He}$ (middle), after reoxidation at $400^{\circ} \mathrm{C}$ with $\mathrm{O}_{2}$ (top).

tionalities become more clear than when the sample was only oxidized. The initial dehydrated Raman features are obtained after reoxidation of this catalyst at $400^{\circ} \mathrm{C}$ under dry air. Furthermore, the absence of Raman bands at 993 , 703,407 and $285 \mathrm{~cm}^{-1}$ indicate that no crystalline $\mathrm{V}_{2} \mathrm{O}_{5}$ was formed. Thus, in situ Raman studies of supported metal oxides during interaction with probe molecules can provide new insights into the surface properties of oxide catalysts.

\section{Conclusions}

A newly developed in situ spectroscopic cell for Fourier transform Raman has been presented. The novel cell allows Raman spectroscopy to be performed under controlled atmosphere (inert gas flow or a stream of reactants) and temperature. This was successfully demonstrated with the thermal conversion of as-synthesized mesoporous titania and with the ethanol oxidation over vanadium oxide grafted MCM-48 materials. The Fourier transform in situ Raman cell can now be used for the characterization of a wide variety of catalyst systems under working conditions.

\section{Acknowledgements}

This work was supported by the Fund for Scientific Research-Flanders (F.W.O.-Vlaanderen), under Research project No. G.0446.99. V. Meynen acknowledges the F.W.O for financial support. P. Van Der Voort and P. Cool are postdoctoral fellows of the F.W.O.-Vlaanderen. The authors are very grateful to J.P. Huysmans for the construction and assembly of the in situ cell.

\section{References}

[1] M.A. Vuurman, D.J. Stufkens, A. Oskam, G. Deo, I.E. Wachs, J. Chem. Soc. Faraday Trans. I 92 (1996) 3259.

[2] G. Deo, I.E. Wachs, J. Phys. Chem. 95 (1991) 5889.

[3] M. Schraml-Marth, A. Wokaun, M. Pohl, H.L. Krauss, J. Chem. Soc. Faraday Trans. 87 (1991) 2635.

[4] G. Mestl, J. Mol. Catal. A Chem. 158 (2000) 45.

[5] B.M. Weckhuysen, R.A. Schoonheydt, Chem. Rev. 96 (1996) 3327.

[6] F. Weesner, M. Longmire, Spectroscopy 16 (2001) 68.

[7] Q. Sun, J.M. Jehng, H. Hu, R.G. Herman, I.E. Wachs, K. Klier, J. Catal. 165 (1997) 91.

[8] G. Koyano, T. Saito, M. Misono, J. Mol. Catal. A Chem. 155 (2000) 31.

[9] G.T. Went, S.T. Oyama, A.T. Bell, J. Phys. Chem. 94 (1990) 4240.

[10] G.T. Went, L.J. Leu, R.R. Rosin, A.T. Bell, J. Catal. 134 (1992) 492.

[11] G. Mestl, M.P. Rosynek, J.H. Lunsford, J. Phys. Chem. 101 (1997) 9321.

[12] J.M. Jehng, G. Deo, B.M. Weckhuysen, I.E. Wachs, J. Mol. Catal. A Chem. 110 (1996) 41.

[13] J.M. Jehng, H. Hu, X. Gao, I.E. Wachs, Catal. Today 28 (1996) 335.

[14] G. Deo, I.E. Wachs, J. Catal. 129 (1991) 307.

[15] X. Gao, S.R. Bare, J.L.G. Fierro, I.E. Wachs, J. Phys. Chem. B 103 (1999) 618.

[16] B.M. Weckhuysen, I.E. Wachs, J. Phys. Chem. 100 (1996) 14437.

[17] M. Boulova, A. Gaskov, G. Lucazeau, Sens. Actuators B 4086 (2001) 1.

[18] J. Wang, X. Xu, J. Deng, Y. Liao, B. Hong, Appl. Surf. Sci. 120 (1997) 99.

[19] Y.T. Chua, P.C. Stair, J. Catal. 196 (2000) 66.

[20] C.T. Kresge, M.E. Leonowics, W.J. Roth, J.C. Vartuli, J.S. Beck, Nature 359 (1992) 710.

[21] M.R. Hoffmann, S.T. Martin, W. Choi, D.W. Bahnemann, Chem. Rev. 95 (1995) 69.

[22] D.T. On, Langmuir 15 (1999) 8561.

[23] M. Thieme, F. Schüth, Microporous Mesoporous Mater. 27 (1999) 193

[24] P. Yang, D. Zhao, D.I. Margolese, B.F. Chmelka, G.D. Stucky, Chem. Mater. 111 (1999) 2813. 
[25] K. Cassiers, T. Linssen, V. Meynen, P. Van Der Voort, P. Cool, E.F. Vansant, Chem. Commun. 1178 (2003).

[26] M.S. Wainwright, N.R. Foster, Catal. Ver. 19 (1979) 211.

[27] G. Deo, I.E. Wachs, J. Haber, Crit. Rev. Surf. Chem. 4 (1994) 141.

[28] G.C. Bond, S.F. Tahir, Appl. Catal. 71 (1991) 1.

[29] O. Collart, P. Van Der Voort, E.F. Vansant, D. Desplantier, A. Galarneau, F. Di Renzo, F. Fajula, J. Phys. Chem. B 105 (2001) 12771.

[30] P. Van Der Voort, M.G. White, E.F. Vansant, Interface Sci. 5 (1995) 179.
[31] P. Van Der Voort, M. Morey, G.D. Stucky, M. Mathieu, E.F. Vansant, J. Phys. Chem. 102 (1998) 585.

[32] M. Baltes, P. Van Der Voort, O. Collart, E.F. Vansant, J. Porous Mater. 5 (1998) 357.

[33] M. Baltes, P. Van Der Voort, B.M. Weckhuysen, R.R. Rao, R.A. Schoonheydt, E.F. Vansant, Phys. Chem. Chem. Phys. 2 (2000) 2673.

[34] P. Viparelli, P. Ciambelli, L. Lisi, G. Ruoppolo, G. Russo, J.C. Volta, Appl. Catal. A General 184 (1999) 291.

[35] T. Ushikubo, K. Wada, Appl. Catal. A General 124 (1995) 19. 